\title{
Fresh and hardened properties of 3D printable cementitious materials for building and construction
}

\begin{abstract}
The main advantage of 3D concrete printing (3DCP) is that it can manufacture complex, non-standard geometries and details rapidly using a printer integrated with a pump, hosepipe and nozzle. Sufficient speed is required for efficient and fast construction. The selected printing speed is a function of the size and geometrical complexity of the element to be printed, linked to the pump speed and quality of the extruded concrete material. Since the printing process requires a continuous, high degree of control of the material during printing, high performance building materials are preferred. Also, as no supporting formwork is used for 3DCP, traditional concrete cannot be directly used. From the above discussion, it is postulated that in $3 \mathrm{DCP}$, the fresh properties of the material, printing direction and printing time may have significant effect on the overall load bearing capacity of the printed objects. The layered concrete may create weak joints in the specimens and reduce the load bearing capacity under compressive, tensile and flexural action that requires stress transfer across or along these joints. In this research, the 3D printed specimens are collected in different orientations from large 3DCP objects and tested for mechanical properties. For the materials tested, it is found that the mechanical properties such as compressive and flexural strength of 3D printed specimen are governed by its printing directions.
\end{abstract}

Key words: 3D concrete printing, 3D printing process, printing direction, rheology, mechanical strengths

\section{Introduction}

In the last two decades, the traditional way of mixing and casting of concrete on site has been replaced, significantly by pre-casting or pre-fabrication in several developed countries. However, the construction sector can still benefit from automation toward reducing labor and construction time, improved quality and reduced environmental impact. In this regard, 3 dimensional (3D) printing was first introduced in 1986 as a means of rapid prototyping [1]. Today, there are different techniques, but the basic principle remains that of additive manufacturing (AM), meaning that material is added layer by layer [2]. 3D printing or AM enables 3D solid objects to 
be "printed" from a digital model by laying down successive layers of material. 3D printers were initially used in industrial environments to produce and refine prototypes also known as rapid prototyping. With reductions in cost and improvements in technology, 3D printing is quickly finding new applications, particularly for short-run manufacturing where customization is important. 3D printing is very useful in the manufacturing of complex geometries, precisely customized parts, parts in a variety of slight variations, or parts that need to be adapted frequently in their manufacturing lifecycle [3-4].

More recently, in a bid to raise construction productivity and to fundamentally change design and construction processes, many countries such as Singapore and Hong Kong are embracing the concept of Design for Manufacturing and Assembly (DfMA) in the construction industry. DfMA is designed for significant amount of work to be done off-site in a controlled manufacturing environment. As a result, Prefabricated Prefinished Volumetric Construction (PPVC) is getting more attention in the construction industry. PPVC is a method whereby free-standing volumetric modules (complete with finishes on walls, floors and ceilings) are either constructed and assembled or manufactured and assembled in an accredited fabrication facility, in accordance with any accredited fabrication method, and then installed in a building under building works. PPVC is one of the game changing technologies that support the DfMA concept to significantly speed up construction. It can potentially achieve a productivity improvement in terms of manpower and time savings, depending on the complexity of the projects. Furthermore, dust and noise pollution can be minimized as more activities are done off-site. With the bulk of the installation activities and manpower moved off-site to a factory controlled environment, site safety will also improve.

The government of Singapore plans to build the city's future public housing by integrating the technology of PPVC strategy for assembly. The idea is to use large-scale 3D printers to build one story at a time before transporting and stacking each floor [5]. Different materials and processes can be used for 3D printing, and printers can range greatly in size, from briefcase sized to those large enough to print houses. The level of definition and the strength qualities of final printed parts can also vary considerably. Successful application of 3D printing in the construction industry can have a huge impact on the total cost of construction. Fig 1 shows that for a new 
concrete construction project, more than $50 \%$ of the total cost is spent for the formwork and labor [6]. Since in 3D printing, no formwork is required and a short project time is required due to continuous work done by the printer, a dramatic reduction in the project cost can be achieved by adopting $3 \mathrm{D}$ printing technique in construction industry.
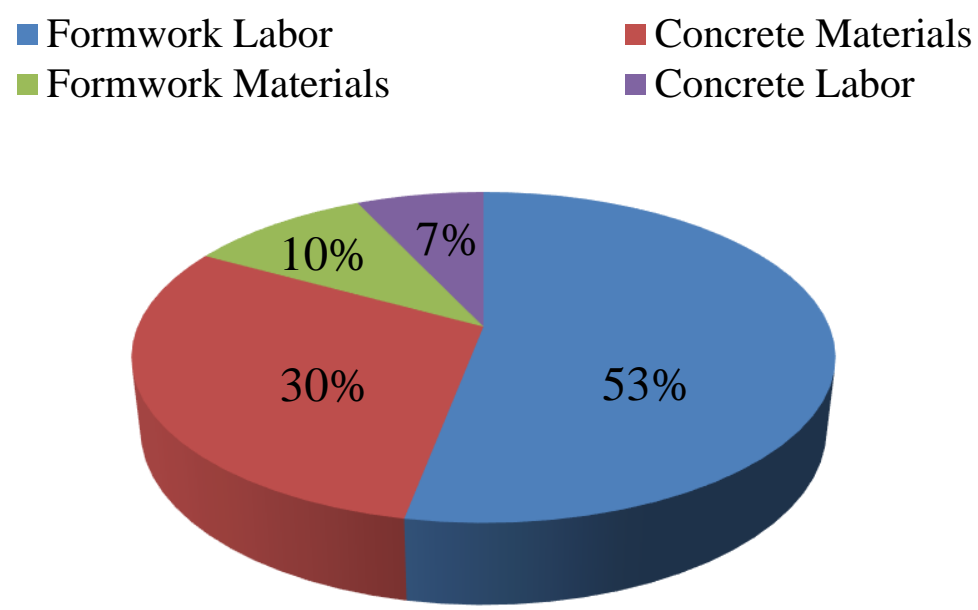

Fig. 1. Typical cost distribution for new concrete construction project [6].

The typical 3D concrete printing (3DCP) process for the construction industry is shown in Fig 2. The whole 3D printing process can be described in two ways. Firstly, the software segment (left side of Fig 2) and secondly, hardware segment (right side of Fig 2). At first, a 3D software such as AutoCAD or Solid Works is used to model the objects, then it is exported to another software for slicing (define the layer dimension). Thereafter, a program file in the form of G-code is generated for the whole object for the printer to read and perform the job as shown in Fig 2. In the hardware segment, an integrated printer (either gantry or robotic) with material delivery system that is connected with a pump and hose pipe are required to deliver the material to the nozzle orifice/head, which is connected at the end part of the hosepipe to deposit the material in layer by layer. A controller is also required to control the printer and pump according to the design (shape, size, etc.) of the printed object. The whole process of 3DCP is already discussed in details by the several researchers [7-10]. 


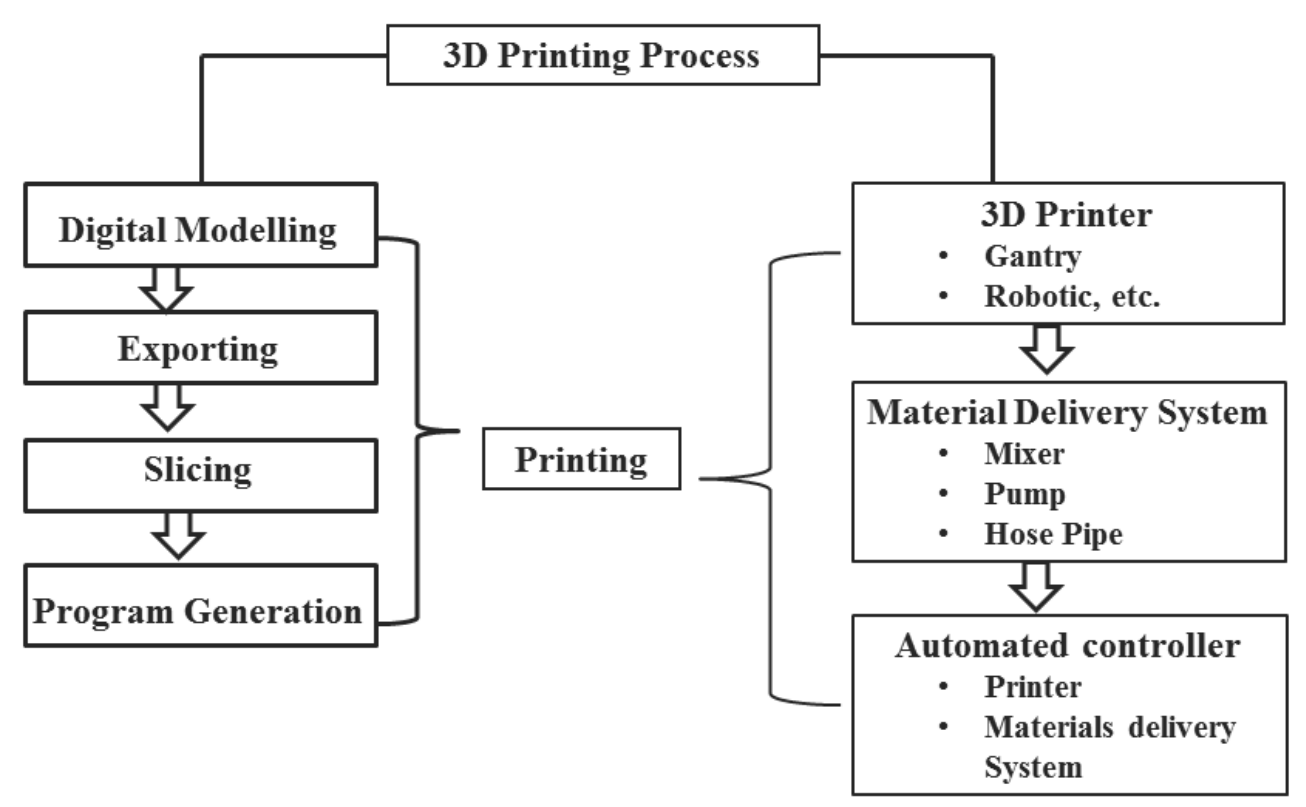

Fig. 2. The process of $3 \mathrm{D}$ printing for construction industry.

While the interest on 3D printing is growing rapidly, however, there are still some concerns about the properties of 3D printed objects, as the manufacturing process is different from the conventional method. In traditional construction, the desire shape of the structure is achieved by pouring concrete in a predefined formwork, while in 3D printing, it is achieved by extruding concrete in layer by layer manner. Therefore, the fresh properties of concrete as well as printing parameters such as printing time, speed, etc. play an important role in the hardened properties of 3D printed objects. Since in 3DCP, no formwork is required to support the concrete layers and material needs to be pumped to the nozzle head for extrusion, the rheology of the fresh properties of printable material becomes very important.

Since no supporting formwork is used for 3D printing, traditional concrete cannot be directly used. For ensuring little or no deformation in the bead layers, an almost zero slump but pumpable concrete is required. However, the production of low slump concrete needs special attention to the granulometric properties of the aggregates. Another important rheological property of fresh concrete is thixotropy. Thixotropy is defined as a decrease in viscosity when shear is applied, followed by a gradual recovery when shear is removed in the fresh material [11-13]. Since in 3DCP, material needs to be pumped and at the same time gain enough strength to carry the load 
from the next layer, therefore, the material thixotropy is important. Else, deformation in the bead layer will occur due to deposition of subsequent layers.

For any type of flow-able material, a good understanding of rheology helps in optimizing the conditions for processing, and in producing good quality products. In the case of concrete/mortar, for example, the proper or improper dispersion of the cement particles in the suspending medium completely changes the rheology of the paste and hence has a tremendous effect on the mixing and placement characteristics of the material. Furthermore, complexities in the rheology can occur when fibers or other reactive components are added to enhance the properties of the products. Improving concrete rheology has a lot to do with the reduction of energy that goes to mixing and vibration of the product for proper placement.

The main aim of this paper is to investigate the fresh and mechanical properties such as slump, thixotropy, viscosity, compressive and flexural strength of 3DCP related to the printing direction. In this respect, three different types of mortar were used to produce the 3D printed objects layer by layer. Thereafter, cube and prism specimens were collected from different directions of the 3D printed mortar objects and their performances were compared with cast specimens. The rheological behavior of different printable mortars is also briefly described.

\section{Properties of 3D printable materials}

One of the main disadvantages of printed structures is their mixed isotropic and anisotropic properties in different direction unlike cast specimens that is taken to have isotropic properties in all directions. Also, the printing quality such as flow behavior of materials, printing speed, printing time gap between the subsequent layers, etc. have significant influence on the final 3D printed objects [14]. In 3D printing, since the final product is constructed layer upon layer, it is expected that the material compatibility is higher in the horizontal direction compared with the vertical direction [15]. Figs 3 and 4 show the possible ways of applying load in different directions of 3D printed object. The tensile strength in the vertical direction ( $\mathrm{z}$ direction) is related to the bond strength among the successive layers. The bond strength is related to many parameters such as material viscosity, printing time gap between the layers, contact area between the successive layers (rectangular nozzle gives more contact area than circular nozzle), etc. It has 
been reported that the direction of loading of the printed specimen has influence on the strength properties [16-18].

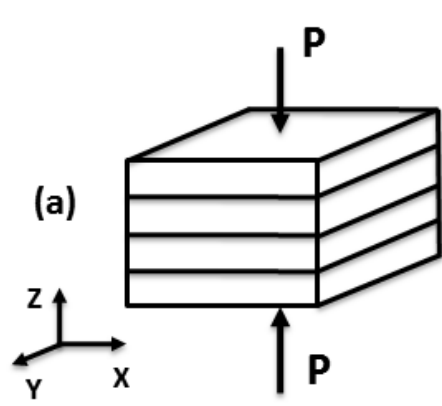

Loading in Z direction (D1) (b)

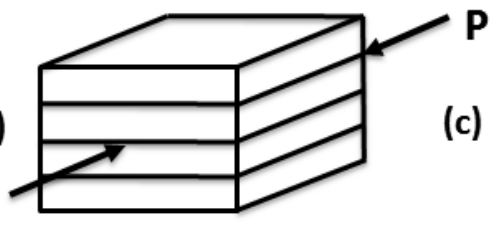

Loading in Y direction (D2)

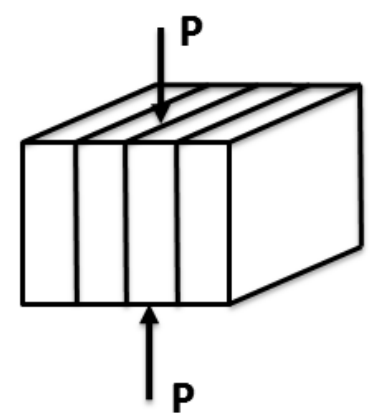

Loading in $\mathrm{X}$ direction (D3)

Fig. 3. Application of compression load in printed objects related to the printing direction

Up to now, most works on 3DCP are done by commercial organization such as Winsun from China, Cybe Construction from the Netherland, Russian company Apis Cor, French based company Xtree rather than research institute. Hence, limited peer reviewed research papers are available on $3 \mathrm{D}$ concrete printing. The available literatures on the properties of 3DCP specimens collected from different printing direction are briefly described.

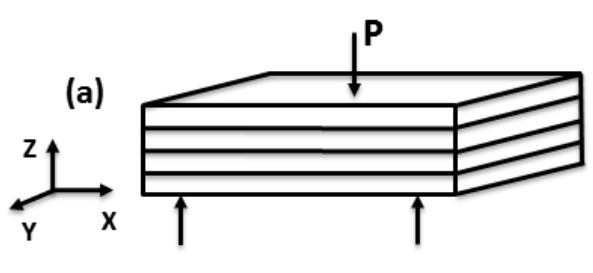

(b)
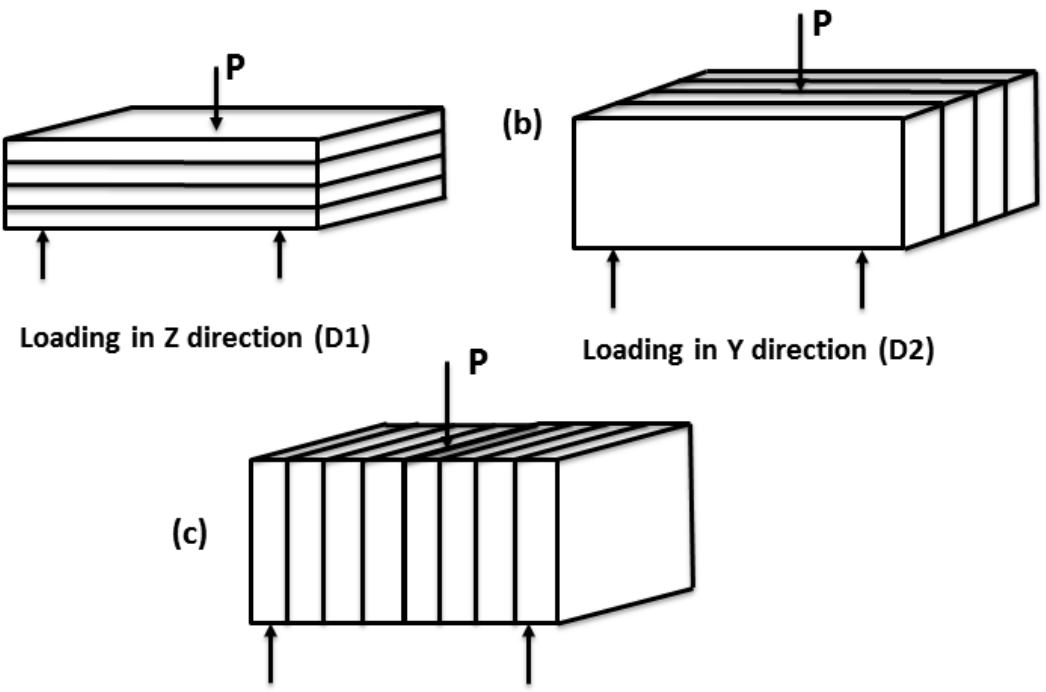

Loading in $\mathrm{X}$ direction (D3)

Fig. 4. Application of flexural load in printed objects related to the printing direction 
Recently, a study by Nerella et al. [17] obtained about $10 \%$ and $14 \%$ increase in the compression strength of printed specimens tested in directions D1 and D3 (see Fig 3), respectively, compared with cast specimens. In the same study, in a flexural strength test, authors have reported about $16 \%$ and 14\% higher strength in printed specimens tested in directions D1 and D3 (see Fig 4), respectively, than in cast specimen. By testing specimens parallel to the layer deposition (see Figs $3 \mathrm{a} \& \mathrm{~b}$ ), Feng et al. [18] obtained higher compressive strength than when testing perpendicular to the layer depositions (see Fig 3c). Nerella et al. [17] also observed similar behaviour. However, the mechanism of this strength variation, which is a function of the test direction, was not explained by the authors. Perhaps, this phenomenon is hard to explain. It is noteworthy that Feng et al. [18] heat cured their specimens and tested at the young age of 3 hours while Nerella et al. [17] did not mention the curing method used. In addition, the layer thickness of the printed specimens in both experiments was significantly different. The layer thickness in Nerella et al. [17] was about $15 \mathrm{~mm}$ x $38 \mathrm{~mm}$ while Feng et al. [18] used a thickness of 0.0875 $\mathrm{mm}$. In both studies, the influence of the printing direction on mechanical properties is clearer. The compressive and flexural strengths were consistently the lowest in testing direction D3 (Fig 3c \& Fig 4c). In this orientation, compressive and flexural splitting may occur along the weak joints in 3D printed concrete specimens.

As mentioned, the printing time and quality may be significant factors influencing the results. Concrete in its plastic state is easy to work with i.e. extrusion process is certainly easier during this state. However, since the hydration of concrete is a continuous process with time, it would eventually reach to its setting state. In this state, it becomes hard to extrude the concrete. Furthermore, the hardening properties of concrete may differ significantly if concrete is disturbed after its plastic state. Once the bulk amount of concrete is prepared for 3D printing, at the beginning, the printing quality is considered to be good, but with time hydration process accelerates and matrix becomes harder (changing plastic to setting state). Over time, some water may also be lost due to evaporation from the mix leading to reduced printing quality. As a result, concrete layers and interfaces of poorer quality might have been created in the upper layers than the bottom layers that were printed much earlier. Obviously, this phenomenon is valid when the object is larger and printing time is longer. For the same reason, mechanical properties of the specimens obtained from the different position of the object would significantly differ. It may 
also contribute to some variation in the results, which could explain the scatter results obtained by Le et al. [16].

From the foregoing, it is postulated that in $3 \mathrm{D}$ printing, the printing direction and printing time have significant effects on the overall load bearing capacity of the printed objects. This underscores the significance of choosing suitable printing direction for $3 \mathrm{D}$ concrete printing.

\section{Experimental design}

After several experiments on different mix compositions, three optimal mixes as shown in Table 1 were chosen to examine the fresh and mechanical behavior relative to the printing direction. The final mix compositions were chosen based on slump value, pumping performance and shape retention after deposition of the bead layer. Importance was given to the materials with minimum slump value but pumpable. Mix 1 is alkali activated geopolymer mortar where no cement is used. To improve the pumpability of Mix 1, rheology modifier such as Actigel and Bentonite clay were used. Potassium silicate $\left(\mathrm{K}_{2} \mathrm{SiO}_{3}\right)$ and potassium hydroxide $(\mathrm{KOH})$ were also used for geoploymerization or as activator in Mix 1. Mixes 2 and 3 are types of printable mortars made from traditional cement, fly ash, silica fume, sand and water. Sodium lignosulfonate was used in both mixes as plasticizer to maintain the rheology with less water. In Mix 3, 0.5\% alkali resistance glass fiber (cut length $6 \mathrm{~mm}$ ) produced by Nippon Electric Glass Co., Ltd, Japan was used to improve the flexural properties.

Table 1. Materials compositions for 3D printed concrete

\begin{tabular}{|l|l|}
\hline \multicolumn{1}{|c|}{ Mix } & \multicolumn{1}{|c|}{ Materials compositions $\left(\mathrm{kg} / \mathrm{m}^{3}\right)$} \\
\hline Mix 1 & $\begin{array}{l}\text { Slag: 39, fly-ash: 645, silica fume: 78, sand: 1168, actigel: 8, bentonite: 8, water: 47, } \\
\mathrm{K}_{2} \mathrm{SiO}_{3}: 250, \mathrm{KOH}: 23 .\end{array}$ \\
\hline Mix 2 & $\begin{array}{l}\text { Cement: 290, fly-ash: 278, silica fume: 145, sand: 1211, water: 285, sodium } \\
\text { lignosulfonate: } 7\end{array}$ \\
\hline Mix 3 & $\begin{array}{l}\text { Cement: 289, fly-ash: 277, silica fume: 145, sand: 1209, water: 284, sodium } \\
\text { lignosulfonate: 9, glass fiber: } 13.5 \text { (density: 2.7, tensile strength: } 1.5 \mathrm{~N} / \mathrm{m}^{2}, \text { young's } \\
\text { modulus: 74 GN/m², failure strain: 2\%) }\end{array}$ \\
\hline
\end{tabular}


Fig 5 shows the grain size distribution of materials used in Mixes 1 and 2. Typically, fine aggregates such as sand is used in 3D concrete printing, and the maximum size of sand is determined based on the pumping capacity of the pump as well as the nozzle size. In this research, the maximum grain size of sand was about $1 \mathrm{~mm}$ as shown in Fig 5.

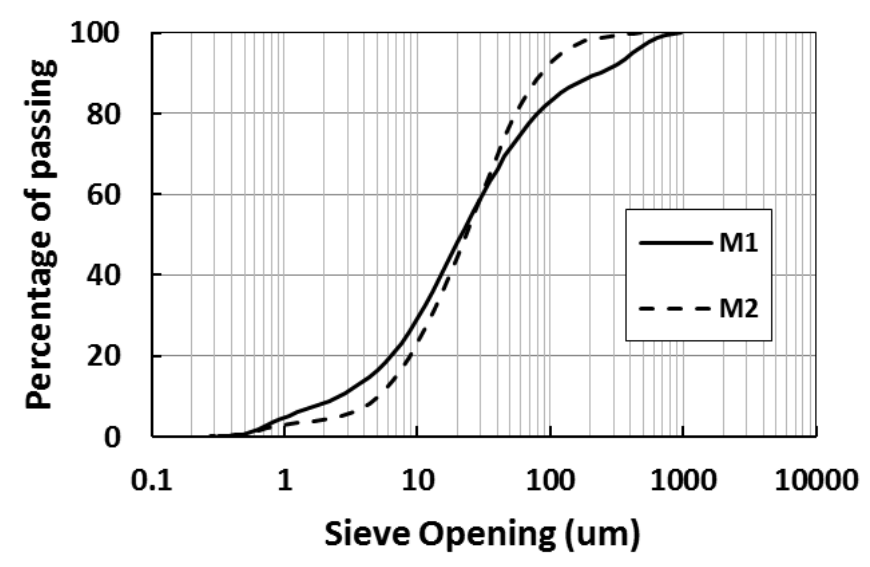

Fig. 5. Particle size distribution in different mix compositions

\subsection{Tests for fresh and mechanical properties}

The workability of the fresh mortars was examined by means of slump flow test and rheology test. A Schleibinger Viskomat XL, Rheometer was used to measure the rheology of the mortars mixes. Typically, rheometer contains a probe in the form of a mixer that measures the torque and the container with 3 liters of fresh concrete, which rotates at different frequencies. A four-blade vane probe (diameter $69 \mathrm{~mm}$, height $69 \mathrm{~mm}$ ) was used to apply the torque in the fresh mortars mixes. Once the material is loaded into the container, flow curve test is performed at increasing speed of $60 \mathrm{rpm}$ up to two minutes followed by two minutes of constant speed, and then reduced to zero in two minutes as shown in Fig 6a. Initially (when material is in rest position) higher torque is required for the vane probe to rotate and the pick value of the torque is considered to the static torque (see Fig 6b). The area of T (Torque) - N (rpm) graph as shown in Fig 6b is used to measure thixotropy, whereas the down curve is considered in calculating the Bingham parameters of the mortar, i.e. plastic viscosity, and shear stress. The plastic viscosity of the material expresses the increase in the shear stress with increase in shear rate. The static yield stress defines the maximum stress required for the material to flow from its rest condition while the dynamic stress is defined as the minimum stress required maintaining the flow [19]. The 
difference in the static and dynamic stresses is due to the thixotropy of the material. However, the shear stress and viscosity of fresh material cannot be obtained directly using viscomat. Therefore, Bingham model for non-Newtonian material (material with yield stress) was used to calculate the expected shear stress and plastic viscosity of the mortars as shown in Eq (1).

Bingham model [20]: $\tau=\tau_{0}+\mu \gamma$

where $\tau$ is the shear stress, $\tau_{0}$ is the yield shear stress, $\mu$ is the plastic viscosity and $\gamma$ is the shear rate.
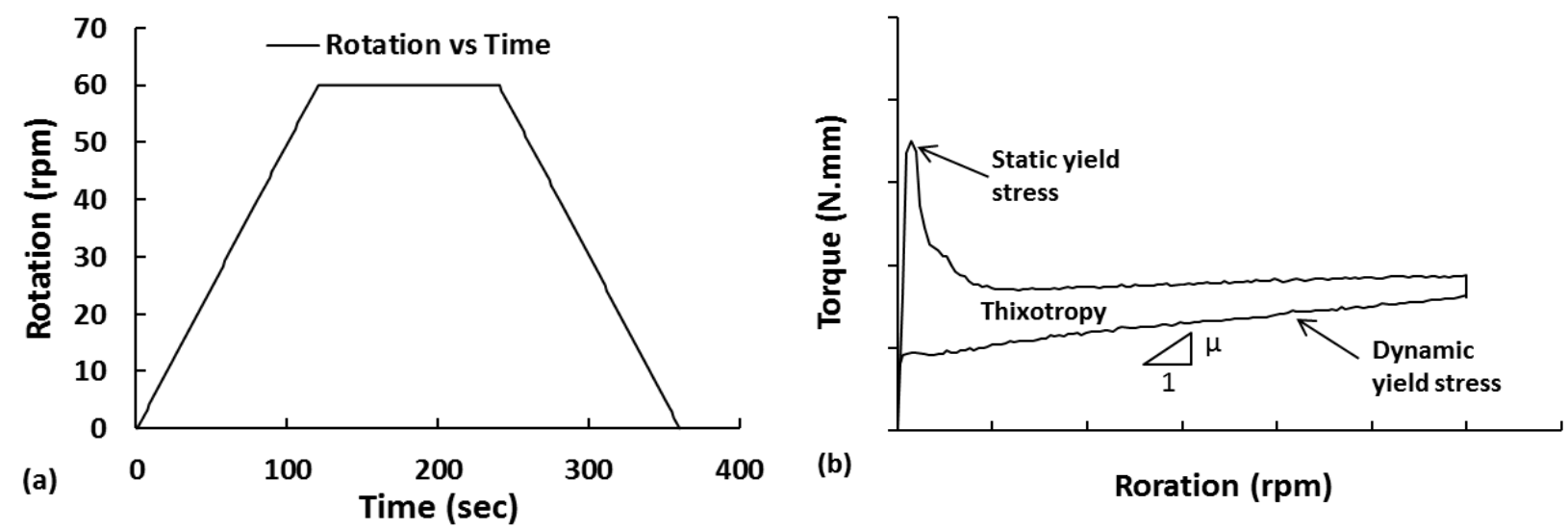

Fig. 6. a) Applied rotation with time for rheology test and b) the flow curve of concrete determination of the hysteresis loop.

For all the mixes, an observation of the open time also known as the time after adding water to the mix to the time when the material reaches its hardened state was carried out. The time was counted from the moment water was added to the mix and until the materials were difficult to pass through the hosepipe to the nozzle orifice during the pumping process. For the mechanical properties, only compressive and flexural strength were determined from both cast and printed objects. In this regard, $50 \mathrm{~mm}$ cube specimens were tested for compression test in accordance with BS EN 196-1:2016 [21]. For printed elements, $50 \mathrm{~mm}$ cube specimens were extracted from the printed objects and tested for 7, 14 and 28 days ( 3 specimens for each direction, giving a total of 9 specimens per test age). Flexural strength was performed using an Instron testing machine for both cast and printed specimens. 18 prism specimens (12 printed and 6 cast) were tested for 
flexural strength. All prism specimens were tested at 7 and 28 days under 3 -point bending following BS EN 196-1:2016 standards [21]. Similar to the compression test, 40 x 40 x $160 \mathrm{~mm}$ prisms were extracted from the printed part and then tested in two directions (three prisms in each direction) and their average values recorded.

\subsection{Printed specimens}

$50 \mathrm{~mm}$ cubes and $40 \mathrm{~mm}$ x $40 \mathrm{~mm}$ x $160 \mathrm{~mm}$ prisms were collected from the different directions of the $3 \mathrm{D}$ printed objects. The 3D printed objects were simple rectangular specimens with maximum dimension of $500 \mathrm{~mm}$ x $150 \mathrm{~mm}$ x $200 \mathrm{~mm}(\mathrm{~L} \times \mathrm{B} \times \mathrm{h})$ as shown in Fig 7. After printing, the objects were left under an ambient temperature of $21 \pm 2^{\circ} \mathrm{C}$ and relative humidity, RH $60 \pm 5 \%$ until cutting and testing. Both cube and prism specimens were collected by cutting on the 3-day from the different printed directions as shown in Figs $3 \& 4$, and then tested for compression and flexural strength test according to BS EN 196-1:2016 [21].
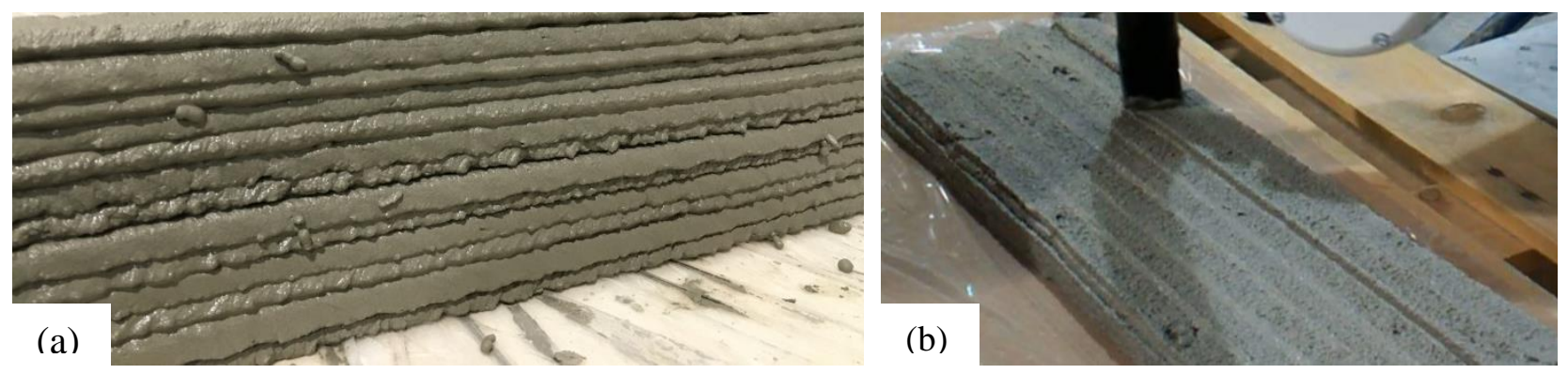

Fig. 7. Printed objects from geopolymer mix 1, a) side view and b) top view

\subsection{D concrete printer and printing parameters}

An autonomous robotic printer was used for concrete printing as shown in Fig 8. A rectangular nozzle with the size of $10 \mathrm{~mm}$ x $20 \mathrm{~mm}$ was used for the geopolymer, Mix 1, as shown in Figure 7, and a nozzle size of $8 \mathrm{~mm}$ diameter was used for mortar, Mixes 2 and 3. The printing speed of the robot was $150 \mathrm{~mm} / \mathrm{sec}$ and the approximate pump flow rate was $3 \mathrm{lit} / \mathrm{min}$. All the Mixes were prepared separately in a concrete mixer and then poured into a hopper of concrete pump where a hose pipe was connected to transport materials to the nozzle orifice (see Fig 8). The pump pressure was in a range of 0.4 to $1.0 \mathrm{MPa}$, and the hose length and diameter was about $3 \mathrm{~m}$ and $25 \mathrm{~mm}$, respectively. 


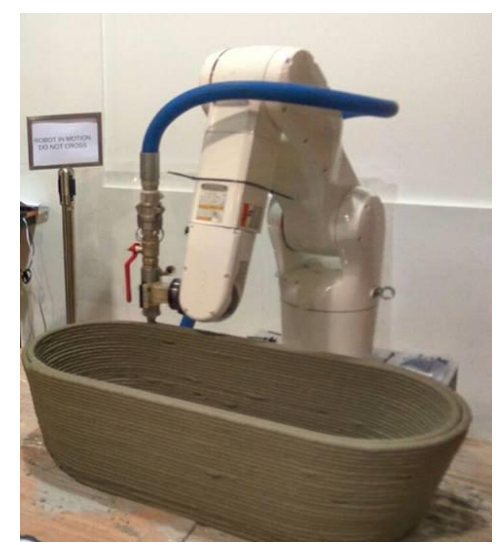

Fig. 8. Autonomous robotic 3D concrete printer

\section{Results and discussion}

\subsection{Workability of $3 D$ printed concrete}

The average slump values in all three mortars were in a range of 1 to $3 \mathrm{~mm}$ (2-6\% of total slump height). A maximum of $3 \mathrm{~mm}$ slump was obtained in the geopolymer, Mix 1. Typical slump behaviour of low slump mortar Mix 2 is shown in Fig 9. Since little or no water is added to the geopolymer mix, the material was sticky making it hard to pump. The open time for the printable materials was in the range of 30 mins for Mix 1 and a maximum of 60 min for other mixes. The open time was determined based on the material pumping ability through the hose pipe to the nozzle. It was noticed that after these specified periods (30 and 60 mins), materials were hard to pump.

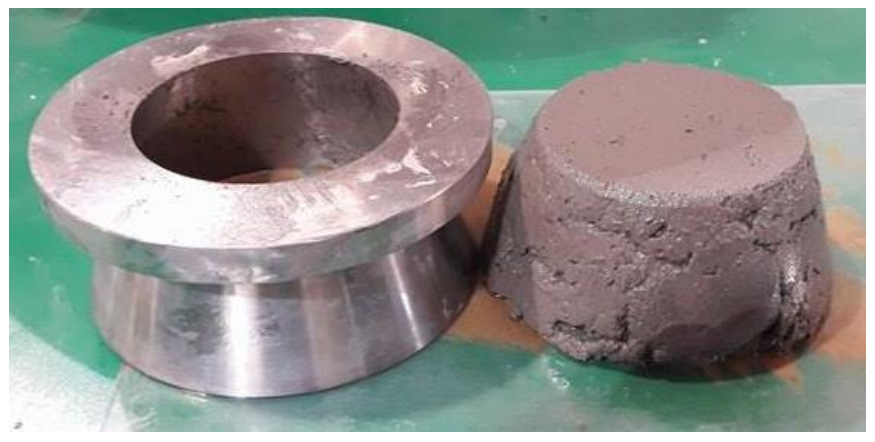

Fig. 9. Slump test of 3D printable mortar Mix 2. 


\subsection{Rheological behavior of $3 D$ printable materials}

As mentioned, the shear stress and viscosity of a fresh material cannot be obtained directly using viscomat. However, Flatt et al. [22] determined the calibration coefficients for the values obtained from viscomat and converted them to shear stress and plastic viscosity. Hence, these calibration coefficients were used to convert the viscomat results reported in Table 2. Typically, the yield stress and plastic viscosity of concrete and mortar such as cement paste grout, mortar, self-compacting concrete (SCC) and normal concrete varies from 10 to $2000 \mathrm{~N} / \mathrm{m}^{2}$ and 0.01 to $100 \mathrm{~N} / \mathrm{m}^{2} . \mathrm{s}$, respectively [11]. Although Banfill [11] reported no range for slump value, however, cement paste grout, mortar, and SCC showed higher slump value. In this study, no limit was found for low slump mortars. However, the results shown in Table 2 prove that the values are certainly higher than the range is given by the Banfill [11].

The rheological behaviors of the mixes are shown in Fig 10. Fig 10a shows the observed torque in different mixes at different applied rotation. Though Mix 1 has a higher slump value ( $3 \mathrm{~mm})$ compared to other mixes, the sticky nature of this material shows a higher plastic viscosity. The inclusion of fibers in Mix 3 leads to a higher static yield torque compared to other mixes as reported in Fig 10a. However, thixotropy, dynamic yield stress and plastic viscosity showed to be lower for Mix 3. The reason of this behavior may be explained by the slippage of the matrix under the applied torque in the viscomat due to the inclusion of fibers. It was also noted that for better pumpability of material, the thixotropy value should be greater than $10000 \mathrm{~N} \mathrm{~mm}$. rpm.

The viscomat values for the mixes reported in Table 2 were calculated from the observed torque at different rotational curve for each mix compositions. Fig 10b shows the calculated shear stress development using Bingham model as shown in Eq (1) for the mixes using the recommended calibration coefficients by Flatt et al. [22]. The higher viscosity of Mix 1 leads to a quicker shear stress development than for other mixes. From the results shown in Table 2, it can be said that the materials static yield stress, thixotropy and viscosity are not related to each other. An example of this statement is Mix 3 where it is found higher static yield stress but lower plastic viscosity than other mixes. 
Table 2. Rheological properties of different 3D printable materials

\begin{tabular}{|c|c|c|c|c|c|c|c|}
\hline \multirow{3}{*}{ Mix } & \multicolumn{4}{|c|}{ Viscomat value } & \multicolumn{3}{|c|}{$\begin{array}{l}\text { Using calibration coefficients (Flatt } \\
\text { et al 2006) }\end{array}$} \\
\hline & $\begin{array}{l}\text { Static yield } \\
\text { torque } \\
(\mathrm{N} \mathrm{mm})\end{array}$ & $\begin{array}{l}\text { Dynamic } \\
\text { yield torque } \\
(\mathrm{N} \mathrm{mm})\end{array}$ & $\begin{array}{c}\text { Slope of the } \\
\text { curve }\end{array}$ & $\begin{array}{l}\text { Thixotropy } \\
\text { (N mm.rpm) }\end{array}$ & $\begin{array}{l}\text { Static } \\
\text { yield } \\
\text { stress }\end{array}$ & $\begin{array}{c}\text { Dynamic } \\
\text { yield } \\
\text { stress }\end{array}$ & $\begin{array}{l}\text { Plastic } \\
\text { viscosity }\end{array}$ \\
\hline & & & & & $\left(\mathrm{N} / \mathrm{m}^{2}\right)$ & $\left(\mathrm{N} / \mathrm{m}^{2}\right)$ & $\left(\mathrm{Ns} / \mathrm{m}^{2}\right)$ \\
\hline Mix1 & 1370 & 358 & 6.3 & 11273 & 13522 & 3534 & 186 \\
\hline Mix 2 & 1401 & 367 & 4.8 & 13756 & 13828 & 3622 & 144 \\
\hline Mix 3 & 1763 & 303 & 3.8 & 17947 & 17401 & 2991 & 113 \\
\hline
\end{tabular}
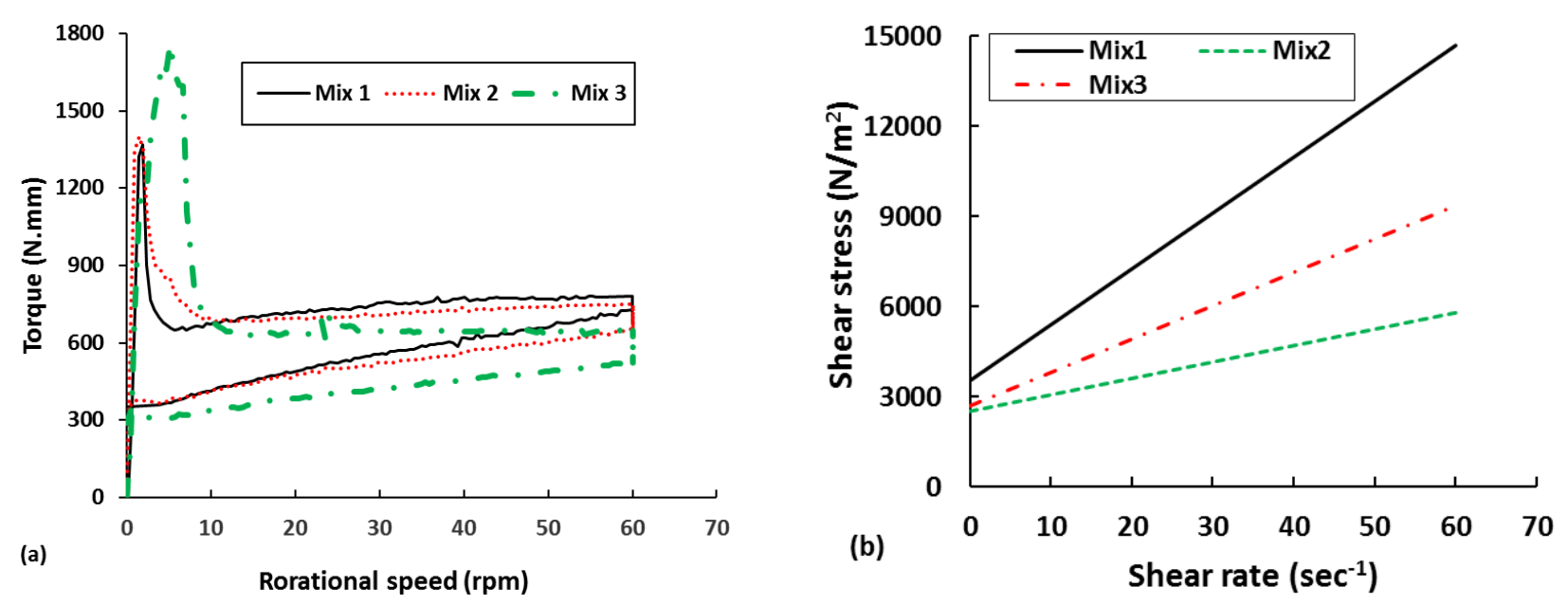

Fig. 10. (a) Rheological behavior (torque at different applied rotation) of all three mixes and (b) calculated shear stress and shear rate of different mortars using Bingham model.

\subsection{Mechanical strengths of $3 D$ printable mortars}

The compressive strength of the 3D printable mortar specimens along with the cast specimens is shown in Fig 11. Compressive strength development was tested up to 28 days for all mixes. Strength development in printed specimens was also compared with the cast/control specimens as shown in Fig 11. It is clear from Fig 11 that the printing direction has influence in the mechanical properties of the printed specimens. The ultimate compressive strengths irrespective of mixes are in the range of $36 \mathrm{MPa}$ to $57 \mathrm{MPa}$. The particular type of geopolymer of Mix 1 reported here has lower ultimate strength (36 MPa) than other mixes. At 28 days of testing, 
specimens collected from the printing direction of D3 are found to have more strength than specimens collected from the other directions including cast specimens. At 28 days, maximum $11 \%$ and $15 \%$ higher strengths were found in the specimens from D3 direction of Mixes $2 \& 3$ than the cast specimen. In Mix 1, this difference was about 1\%. This higher strength in the D3 direction is an agreement with the results obtained by Feng et al. [18] and Nerella et al. [17]. In D3 direction, both authors found about 15\% higher strength in compare to the cast specimens. It is also important to note that the specimens printed by rectangular nozzle orifice using Mix 1 showed almost similar trend in the strength development as the control specimens, while specimens printed from the circular orifice using Mixes 2 and 3 showed a large variation in the strength development.

Previous research on single layer extruded material reported that the mechanical strength of extruded specimens could be higher than for cast specimens [23]. The mechanism of this higher strength was explained by the formation of denser matrix during extrusion process. In the extrusion process, certain amount of pressure is applied to the fresh state of the material, which helps in reducing the voids in the extruded specimen, and ultimately, higher strength can be achieved. However, for the multiple layers of extruded specimens, this phenomenon may not be dominant as other factors such as nozzle shape, complexity of printed objects also influence the mechanical properties.

Similar to the compressive strength, the difference in the flexural strength was also observed as it is shown in Fig 12. It should be noted that only the specimens from Mix 1 were used for this test. Also for printed specimens, the strength was determined only at two different printing directions as shown in Fig 12. At 28 days, maximum $6 \%$ and $12 \%$ less flexural strength was found in control specimen than the specimens collected from direction D1 and D2. This outcome also proves the result found by Nerella et al. [17], where maximum 14\% higher flexural strength was found in the specimens tested in D2 direction than cast specimens. 

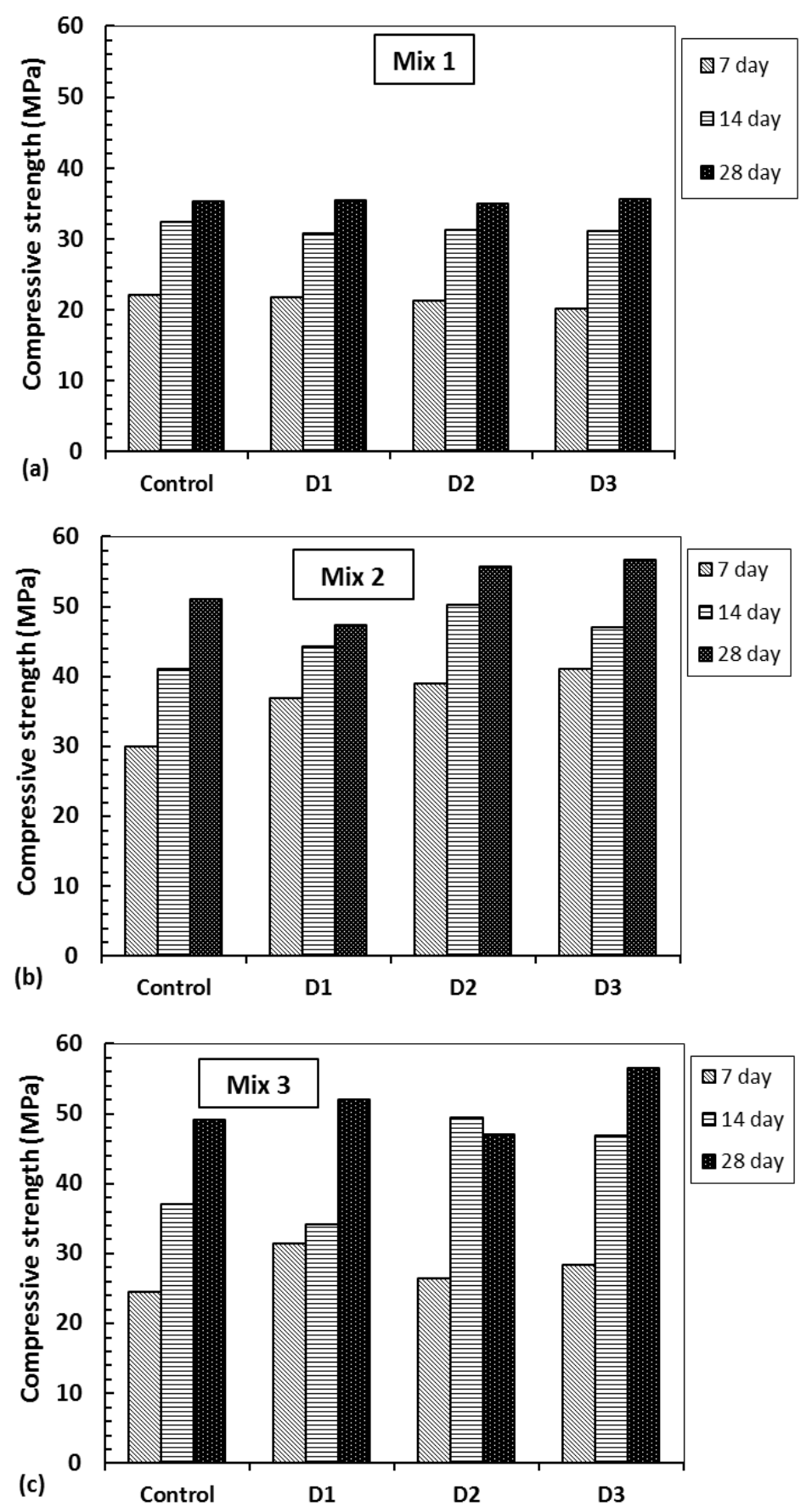

Fig. 11. Compressive strength of cast and printed specimens of different mixes 


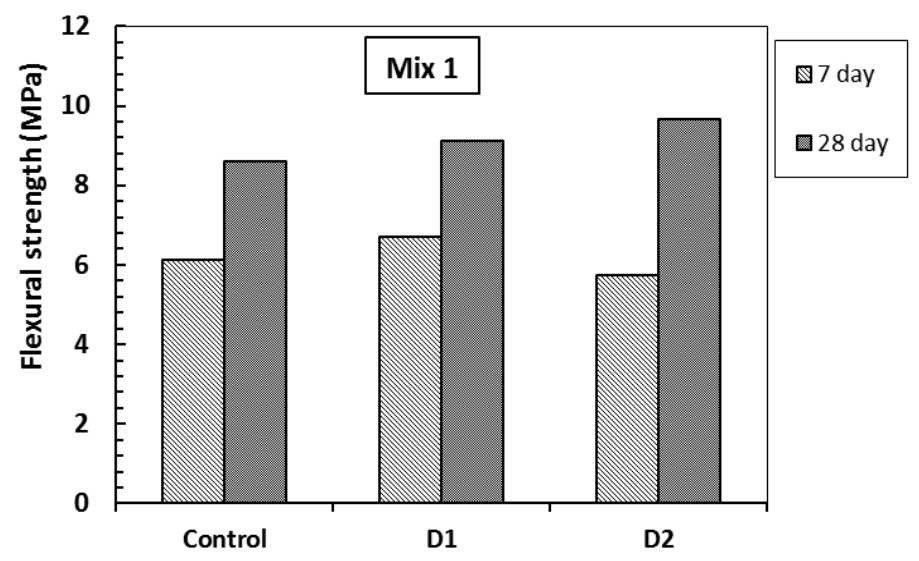

Fig. 12. Flexural strength of cast and printed specimens of Mix 1.

The variation in the results was also observed for the circular and rectangular nozzles. Circular nozzle creates many voids/holes in the printed object as demonstrated in Fig 13a, which may lower the strength as shown in Figs 11 b\&c. However, in the case of rectangular or square nozzle, this problem may not be significant (see Fig 11a). Circular nozzle is good for printing any complex object since at different rotational angle; the nozzle can maintain a symmetric section. Whereas for other types of nozzles, this may be difficult to achieve as it is demonstrated in Fig 13b. It is clear from Fig 13 that square nozzle position falls outside the printing path while the circular nozzle maintains the right alignment. Therefore, it can be postulated that in 3D printing, the mechanical properties of the material is also controlled by printing parameters such as nozzle size, printed objects, etc. which need to be considered while designing any structure for $3 \mathrm{D}$ printing.

Finally, this study is focused on the fresh and hardened properties of $3 \mathrm{D}$ materials related to pumpability and printing direction. The ongoing research by the authors is endeavored more on fresh and mechanical properties such as green strength of materials, influence of different curing methods on materials properties, bond strength between the layers, shrinkage behavior and addition of reinforcement in the printed layers. The outcomes of these tests results are going to be included in the subsequent publications by the authors in future. 


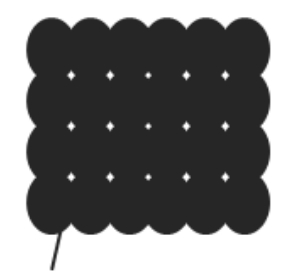

(a)
Voids between the bead layer

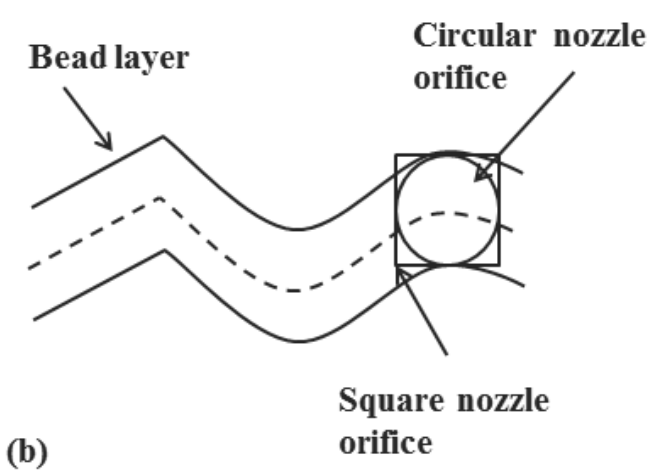

(b)

orifice

Fig. 13. Printing problems for different nozzle orifice a) voids between the circular bead layers and b) misalignment of bead layer due to nozzle orifice

\section{Conclusions}

In recent times, 3D concrete printing (3DCP) is considered an emerging high-tech development in construction technology. However, it is too early to say whether 3DPC can fully replace current concrete construction methods such as cast-in-situ and pre-fabricated parts. At this moment, it is necessary to find the complexity in the current construction methods and justify whether the $3 \mathrm{D}$ printing can be used to remove that complexity. A current limitation and research need of 3DCP in the building and construction (B\&C) industry lies in automated horizontal and vertical reinforcement. This can contribute to $\mathrm{B} \& \mathrm{C}$ automation by $3 \mathrm{DCP}$, which can eliminate formwork and produce complex 3D geometries with minimal time and human interaction and high geometrical precision. It is imperative that characterization of the hardened properties is also performed according to standardized test procedures to enable appropriate engineering design. Nevertheless, the potential of automation, elimination of formwork, reduced or eliminated waste, and production of complex geometries renders 3DCP as an exciting prospect for the construction industry. This could justify intense research and development to bring the technology to realization. This research work has presented important parameters for consideration in $3 \mathrm{D}$ printable construction materials. From the results shown in this study, the following conclusions can be drawn:

- No relationships exist among the yield stress, thixotropy and viscosity properties of 3D printable materials. 
- To ensure the better pumpability of 3D printable materials, the thixotropy value should be greater than $10000 \mathrm{~N}$ mm.rpm.

- The printing direction influences the mechanical properties of 3D printed specimens. Depending on the testing direction, both increase and decrease trend in the mechanical strength can be found in the printed specimen when compared to the strength of cast specimen.

- The mechanical properties of 3D printed specimens are controlled by printing parameters such as shape of the nozzle orifice, complexity of the printed objects.

Finally, prior to the acceptance of $3 \mathrm{D}$ printing as a new construction technology by $\mathrm{B} \& \mathrm{C}$ authorities, standards for materials, specification, manufacturing and structural design are required. These standards and their appropriate application in design and construction must ensure that appropriate levels of reliability are achieved. In the simplest form, this might be achieved by bringing additional considerations and requirements to the attention of structural designers, analogous to precast construction, to which a separate chapter is devoted in Eurocode 2 for concrete buildings.

\section{References}

[1] C.W. Hull, Apparatus for production of three-dimensional objects by stereolithography, 1986, US Patent 4575330.

[2] I. Gibson, D.W. Rosen, B. Stucker, Additive manufacturing technologies: 3D Printing, Rapid Prototyping, and Direct Digital Manufacturing, Springer, 2015. DOI 10.1007/978-1-4939-21133-1.

[3] C. McAlister, J. Wood, The potential of 3D printing to reduce the environmental impacts of production, ECEEE Industrial Summer Study Proceedings 2014 213-221.

[4] B. Khoshnevis, Automated construction by contour crafting - related robotics and information technologies, Automation in Construction 2004 13, 5-19.

[5] Prefabricated Prefinished Volumetric Construction (PPVC): Available at https://www.bca.gov.sg/BuildableDesign/ppvc.html (accessed on 20 ${ }^{\text {th }}$ December 2016) 
[6] K.N. Jha, Formwork for Concrete Structures. Tata McGraw Hill Education Private Limited, New Dilhi, India, 2012. ISBN (13): 978-1-25-900733-0.

[7] F. Bos, R. Wolfs, Z. Ahmed, T. Salet, Additive manufacturing of concrete in construction: potentials and challenges of 3D concrete printing, Virtual and Physical Prototyping 2016. DOI: 10.1080/17452759.2016.1209867.

[8] Y.W. Tay, B. Panda, S.C. Paul, M.J. Tan, S. Qian, K.F. Leong, C.K. Chua, Processing and properties of construction materials for 3D printing, Materials Science Forum 2016 861, 177181.

[9] R.J.M. Wolfs, 3D printing of concrete structures, MSc thesis, Eindhoven University of Technology, The Netherlands, 2015.

[10] S. Lim, R. Buswell, T. Le, R. Wackrow, S.A. Austin, A. Gibb, T. Thorpe, Development of a viable concrete printing process, In proceeding for 28th International Symposium on Automation and Robotics in Construction (ISARC2011), Seoul, South Korea (2011), 665-670.

[11] P. F. G. Banfill, Rheology of fresh cement and concrete, Rheology Reviews 200661 - 130.

[12] N. Roussel, A thixotropic model for fresh fluid concretes: Theory, validation and applications. Cement and Concrete Research 200636 1797-1806.

[13] K.H. Khayat, J.J. Assaad, Effect of w/cm and high-range water-reducing admixture on formwork pressure and thixotropy of self-consolodating concrete, ACI Materials Journal 2006 103(3) 186-193.

[14] J.J. Lewandowski, M. Seifi, Metal Additive Manufacturing: A Review of Mechanical Properties, Annual Review of Materials Research 2016 46(1) 14.1-14.36.

[15] G.P.A.G. Van Zijl, S.C. Paul, M.J. Tan, Properties of 3D Printable Concrete, In proceedings of the $2^{\text {nd }}$ International Conference on Progress in Additive Manufacturing (Pro-AM 2016), Research Publishing, Singapore (2016), Research Publisher, 421-426.

[16] T.T. Le, S.A. Austin, A. Lim, R.A. Buswell, R. Law, A.G.F. Gibb, T. Thorpe, Hardened properties of high-performance printing concrete, Cement and Concrete Research 2012 42(3) $558-566$.

[17] V.N. Nerella, M. Krause, M. Näther, V. Mechtcherine, Studying printability of fresh concrete for formwork free Concrete on-site 3D Printing technology (CONPrint3D), In 
Proceeding for the $25^{\text {th }}$ Conference on Rheology of Building Materials, Regensburg, Germany, 2016.

[18] P. Feng, X. Meng, J.F. Chen, L. Ye, Mechanical properties of structures 3D printed with cementitious powders, Construction and Building Materials 201593 486-497.

[19] P.F.G. Banfill, The rheology of fresh cement and concrete - a review, In Proc 11th International Cement Chemistry Congress, Durban, South Africa, 2003.

[20] H A. Barnes, A handbook of elementary rheology, Institute of Non-Newtonian Fluid Mechanics, University of Wales, UK, 2000. ISBN 0-9538032-0-1.

[21] BS EN 196-1:2016: Methods of testing cement. Part 1: Determination of strength, BSI Standards Limited 2016, ISBN 9780580845802.

[22] R.J. Flatt, D. Larosa, N. Roussel, Linking yield stress measurements: spread test versus viskomat, Cement and Concrete Research 2006 36 99-109.

[23] D. De Koker, Manufacturing processes for engineered cement-based composite material products, MSc thesis, Stellenbosch University, South Africa, 2004. 